\title{
MÉTODOS EDUCACIONAIS DE CRIANÇAS E ADOLESCENTES
}

\author{
Andreas Gabriel Ferreira Miranda \\ Universidade do Oeste Paulista - UNOESTE, curso de Direito, Presidente Prudente, SP. E-mail: \\ andreasferreira50@gmail.com
}

\begin{abstract}
RESUMO
A educação familiar é um projeto de formação e instrução para a cidadania e a ética. O ser humano não nasce só, não estando apto em seu físico ou psicológico para viver só, assim desde a infância a família possui um caráter importante para vivência e educação social dos indivíduos. 0 presente estudo tem por objetivo demonstrar a efetividade da educação familiar eficiente e que resguarde a integridade do indivíduo, para que não tenha danos futuros na formação do caráter do mesmo. A metodologia constou de pesquisa em artigos sobre os modelos educacionais, e a fundamentação legal sobre o modelo atual da educação do país. Concluímos que a melhoria da educação familiar não se dá pela criação de diplomas legais, porém, pela educação de todos os entes responsáveis pela formação do caráter da criança e do adolescente.
\end{abstract}

PALAVRAS-CHAVE: Educação. Punição. Castigo. Criança. Adolescente.

\section{EDUCATIONAL METHODS OF CHILDREN AND ADOLESCENTS}

\begin{abstract}
Family education is a project of formation and instruction for citizenship and ethics. The human being is not only born, and is not physically or psychologically able to live solitary, so since childhood the family has an important character for living and social education of individuals. The purpose of this study is to demonstrate the effectiveness of effective family education and to safeguard the integrity of the individual so that there is no future damage to the character formation. The methodology consisted of research on articles on educational models, and the legal basis on the current model of education in the country. We conclude that the improvement of family education is not due to the creation of legal diplomas, but by the education of all the entities responsible for the formation of the character of the child and the adolescente.
\end{abstract}

KEYWORDS: Education. Punishment. Punishment. Child. Teenager.

\section{INTRODUÇÃO}

A educação de jovens e crianças no Brasil do século XXI, passa por um complexo processo de modificação. O modelo educacional que até então era considerada como o mais usual sofreu alterações significativas com advento de métodos inovadores de instrução e compreensão da integridade física de crianças e adolescente, baseado na crescente valorização dos direitos a personalidade, porém, uma série de requisitos devem ser analisados para saber se a alteração elaborada em forma de diplomas legais possui a aceitação da população, ou se sua efetividade consegue alcançar diversos âmbitos dentro dos lares.

O presente trabalho busca mostrar a importância de uma educação adequada para a criança e adolescente, para a manutenção de uma vida digna, na tentativa de preservação física e psicossocial do grupo tutelado pelo ECA, que por suas condições é muito fragilizado, fazendo isto 
por meio da busca das causas de agressões e, possíveis soluções cabíveis na utilização da lei em casos onde encontrado indícios da violação e pratica agressiva contra a criança e adolescente.

\section{METODOLOGIA}

O presente trabalho foi elaborado utilizando de estudos realizados por diversas áreas, como educação, saúde e ciência sociais.

Para o desenvolvimento fez se necessária a seleção de artigos, livros e sites que abordam a temática de problemas educacionais, correlacionando-os com os diplomas legais brasileiros, que mediante a normatização legislativa, também atua como defensor das mudanças no âmbito educacional das famílias e comunidade. Por esse método conseguir resultados que façam entender as falhas do ato de legislar sem a integração com a realidade social.

\section{DISCUSSÃO}

A discussão que motivou a elaboração do presente estudo está na problemática enfrentada por crianças e adolescentes na garantia de seus direitos a integridade física e psíquica, que vincula as falhas ao sistema educacional adotado pela maioria das famílias, na tentativa de encontrar a falha e propor soluções para melhor efetivação da proteção da população infantojuvenil.

\section{GARANTIA A INTEGRIDADE FÍSICA, MORAL E PSÍQUICA}

Quando falamos em integridade remetemo-nos aos Direitos da personalidade, que é inerte a pessoa humana sendo: intransmissíveis, irrenunciáveis e imprescritíveis tais direitos estão proclamados no Art. 11 do Código Civil, onde vem expresso de maneira taxativa com a seguinte redação: "com exceção dos casos previstos em lei, os direitos da personalidade são intransmissíveis e irrenunciáveis, não podendo seu exercício sofrer limitação temporária". (PLANALTO , 2002), tais direitos também são garantidos constitucionalmente pela Constituição da República Federativa do Brasil em seu art. $3^{\circ}$ onde trata das garantias fundamentais.

Para a educadora Lívia Vieira a Lei da Palmada que após sua criação modifica o ECA (Estatuto da Criança e Adolescente), criando uma proteção eficaz a integridade da criança enfatizando que é necessário que se crie novas maneiras, novos costumes que não sejam castigos corporais, "Não têm nada mais humilhante. Dói, na alma" (CMAIS, 2011)

Todo ser humano possui o direito sobre seu corpo, a violação desse direito coloca em risco as garantias essenciais para o bem-estar da pessoa humana, e colocar em risco toda uma estrutura social. A desconsideração do direito sobre o corpo de crianças e adolescente fere profundamente esses indivíduos, lesa garantias fundamentais que lhes são garantidas desde o nascimento, e de acordo com a teoria concepcionista, até mesmo anterior ao nascimento quando o nascituro está na fase embrionária, supondo que o mesmo vira a nascer com vida, sendo claramente expresso em nosso ordenamento jurídico como garantia fundamental ao ser humano, não limitando a idade, raça, credo ou opção de gênero. (RODRIGUES, 2007)

A violação da integridade da criança e adolescente gera uma serie de danos que a longo prazo podem se tornar irreparáveis, esses danos não estão limitados aos físicos como ocorre em casos mais graves onde o nível das violências pode ocasionar a amputação de membros, ou como em casos mais severos a morte, inclui-se também aos tipos de violação os danos psicológicos, que por sua vez tornam se mais devastadores para o indivíduo, criando marcas que o acompanham durante toda a vida e que normalmente são transmitidos para os seus descendentes, na forma de resposta involuntária do dano que Ihe foi causado em outros tempos. 
Segundo Márcia Oliveira, oficial de Programa para a América Latina e o Caribe da "Save the Children" Suécia, os castigos físicos no Brasil tem mudado com a história, mas só a partir de 2005 é que alguns grupos regionais começaram a aderir à ideia de não castigar fisicamente as crianças e adolescente.

Em seu estudo Márcia de Oliveira defende:

A violência punitiva no Brasil começou com os escravos, depois com a mulher. A mulher lutou muito contra isso e nem em relacionamentos é mais permitido qualquer tipo de agressão, principalmente depois da lei Maria da Penha. Até com os animais é proibido o uso violência, nos circos existe todo um cuidado, uma cobrança. Só com as crianças que a violência física continua sendo permitida. Temos que pular esta etapa de igual forma, ainda mais quando o que sustenta esta prática é o mito da validade do castigo com fins de educação (OLIVIERA, 2010)

Muitos indivíduos não percebem que os castigos físicos são humilhantes, os agressores normalmente foram submetidos a crueldade na infância, gerando por isso, em quase todos os casos transtornos psíquicos que são repassados da mesma forma como torturas psicológicas e em casos mais graves lesões físicas. A crueldade dos castigos deve ser considerada um flagelo a identidade moral da criança e adolescente, não ferindo apenas a lei, mas marcando vidas que tornam a longo prazo baseadas em marcas, hematomas e transtornos sociais e psicológicos, modificando a futuro e o meio de pensar gerando interferência no meio educacional que seguira os modelos da educação recebida por esses indivíduos, que futuramente irão proporcionar aos ascendentes tratamento semelhante, por considerar o mais correto.

\section{FILHOS O REFLEXO DOS PAIS}

Em pesquisa realizada pela Universidade Federal do Paraná onde foram analisados 1.485 ( um mil quatrocentos e oitenta e cinco), adolescentes entre 14 e 17 anos, buscando demonstrar a ineficácia de punição para a educação de jovens e menores, ilustra com clareza que as punições físicas e psicossociais não possuem caráter de benfeitorias as vítimas, os pesquisadores afirmam: "É jogar luz sobre a conduta que os pais devem ter na educação das crianças: o ideal é saber dialogar, dizer não, negociar, estabelecer regras e limites e pedir desculpas para seus filhos". (BERTOTTI, 2009)

A lei que institui a proibição de castigos físicos e psicológicos vem trazendo uma serie de melhoria na vida de crianças e adolescentes, oportunizando-os a formação do caráter sem os reflexos negativos dos castigos, que podem ser transmitidos a gerações futuras, a lei traz mudança no que se chama de "cultura da violência, com a utilização de frases como: 'Meu pai me bateu, por isso eu bato nos meus filhos" (RODRIGUES, 2010)[grifo nosso]. Em afirmações como a citada, é possível notar marcas de danos ocasionados ao agente por ocasião dos castigos, que são repassados por meio da utilização dos castigos físicos, mostrando assim a ineficácia e crueldade dos mesmos, a violência física ou psicológica gera um ciclo interminável de diversas formas de agressão, limitando os reflexos educacionais que a família tem como obrigação na contribuição da formação intelectual e psicológica dos filhos. (NASCIMENTO, SILVA, et al., 2002)

A educação deve ser proporcionada de maneira a não ferir direitos garantidos constitucionalmente como o direito a integridade física e psíquica no Art. $5^{\circ}, \mathrm{XLIX}$ onde é tratado a respeito da integridade física e moral dos presidiários (PLANALTO, 2017), assegurar o direito a integridade física e moral é método mais eficaz para a validade das normas constitucionais, a 
criação de meios que proporcione as crianças e adolescente um ambiente familiar livre de violência certamente assegurará um futuro mais digno a todos.

A maior parte dos casos onde adolescente é encaminhada a centro de recuperação juvenil percebe-se que os fatos que influenciaram a prática delituosa vêm da vida cotidiana dentro do lar, ocasionada pela negligência dos pais dentro do âmbito familiar. (NASCIMENTO, SILVA, et al., 2002)

Sendo assim educar de maneira consciente trará melhoras nos fatores que ocasionam a entrada dos indivíduos em vidas deturpadas pelo crime, negligencia e falta de compreensão social e familiar.

\section{CASTIGOS FÍSICOS: CRUELDADE DISFARÇADA DE EDUCAÇÃO}

O castigo físico em crianças pode gerara transtornos mentais (JEANE LESSINGER BORGES, 2008), chegando a concepção de que além dos abusos sexuais ou exploração os castigos físicos também estão entre as formas de agressão que mais causam transtornos mentais em crianças e adolescentes.

As agressões mesmo não sendo formas de abuso tão graves, como sexual ou negligência, que já trazem a comprovação de serem prejudiciais à saúde mental alguns como empurrar, bater e agarrar se associam a distúrbios de ansiedade e de personalidade. De acordo com os autores do trabalho, "mostra se clara a relação entre maus tratos tanto físicos e emocionais quanto abuso sexual contra crianças, e a influência em problemas emocionais apresentados por elas durante a vida adulta". (JEANE LESSINGER BORGES, 2008)

A educação não precisa se maquilhar de agressão para que seja efetiva, o ser humano possui racionalidade, poder cognitivo, não deve valer-se da força física para fazer sua vontade ser atendida.

\section{DIREITO PENAL E A DEFESA DA CRIANÇA E ADOLESCENTE}

A aplicação do artigo $1^{\circ}$ do Estatuto da Criança e Adolescente requer cada vez mais dos aplicadores do direito uma ponderação e atenção em relações jurídicas, o direito reservado a essa parcela da população está em constante desenvolvimento, trazendo cada vez mais artigos, entendimentos e defensores do direito da Criança e Adolescente.

Ao conceituar o direito de Proteção à Infância e Adolescência Alexandre Fernandes Spizzirri trata como: "o conjunto de normas penais que protegem a criança e adolescente, ou seja, ao conjunto de dispositivos penais que tem a criança e adolescente vitimadas" (SPIZZIRRI, 2008).

No Título VII do Livro II do Estatuto da Criança e Adolescente, em artigos específicos do Código Penal ou de leis complementares trazem a importância da proteção e garantia do direito penal para a infância e juventude. (PLANALTO , 1990).

Caso o Direito Penal não tutele o bem da Criança e Adolescente nada poderia se fazer contra os agressores das mesmas, visto que, todas as agressões à criança geram danos, composto em sua maioria por abusos sexuais e físicos, e plenamente cabível a tutela e defesa desta espécie de delito ao ramo Penal, nota-se neste o valor inexcusável da tutela penal para a benfeitoria da criança e adolescente no mundo atual, sendo um importante aliado junto com os educadores, famílias e demais entidades responsáveis pela defesa e garantia das melhores condições de vida a criança e ao adolescente.

A atuação criminal voltada para a criança e adolescente requer dos criminalistas a melhoria da técnica jurídica, as aplicações que outrora eram utilizadas para defesa desse grupo na atualidade e frente a realidade da sociedade tornaram-se obsoletas, tendo de ser reciclado para que haja a efetividade do resguardo dos direitos fundamentais a criança e adolescente, e a criação 
de um meio sem lacuna de o estado se impor sua sanção contra qualquer indivíduo que não observe as garantias do público.

\section{TIPOS DE VIOLÊNCIA SOFRIDA POR CRIANÇAS E ADOLESCENTES NO BRASIL}

$O$ nível de violência sofrida por crianças entre as faixas etárias de 0 a 18 anos são significativas no Brasil, no gráfico a cima notamos o grande nível de vulnerabilidade desses público com os números de casos de violência sofrida dentro do âmbito familiar, do ano de 2010 até o presente momento, nota-se o aumento dessa espécie de violência significativamente, mostrando à ineficiência dos órgãos de proteção à criança e adolescente no país (GONÇALVES e SPOSITO, 2002). A lei não deve estar apenas no papel, os mecanismos de aplicação dessa lei devem ser muito bem amparados e, aparelhados com todos os materiais necessários para a efetivação das garantias previstas nos diplomas legais.

De acordo com o Site da UNICEF Brasil os tipos de violência sofrida pelo público criança e adolescente tem a variedade muito amplo sendo algum deles:

Tortura: Atos intencionalmente praticados para causar lesões físicas, ou mentais, ou de ambas as naturezas com finalidade de obter determinada vantagem, informação, aplicar castigo, entre outros.

Violência Psicológica: Relação de poder com abuso da autoridade ou da ascendência sobre o outro, de forma inadequada e com excesso ou descaso. Coerção.

Discriminação: Distinção, segregação, prejuízo ou tratamento diferenciado de alguém por causa de características pessoais, raça/etnia, gênero, religião, idade, origem social, entre outras.

Violência Sexual: Situações de abuso ou de exploração sexual de crianças e adolescentes. Implica a utilização de crianças e adolescentes para fins sexuais, mediada ou não por força ou vantagem financeira.

Violência Física: Ato de agressão física que se traduz em marcas visíveis ou não

Negligência e Abandono: Abandono, descuido, desamparo, desresponsabilizarão e descompromisso do cuidado. Ato que não está necessariamente relacionado às dificuldades socioeconômicas dos responsáveis pela criança ou pelo adolescente.

Trabalho Infantil: É todo o trabalho realizado por pessoas que tenham menos da idade mínima permitida para trabalhar. No Brasil, o trabalho não é permitido sob qualquer condição para crianças e adolescentes até 14 anos. Adolescentes entre 14 e 16 podem trabalhar, mas na condição de aprendizes. Dos 16 aos 18 anos, as atividades laborais são permitidas, desde que não aconteçam das $22 \mathrm{~h}$ às $5 \mathrm{~h}$ e não sejam insalubres ou perigosas.

Tráfico de crianças e adolescentes: Recrutamento, transporte, transferência, alojamento ou acolhimento de uma criança ou um adolescente para fins de exploração. (UNICEFE, 2017)

O pior tipo de infrator a se punir é aquele que tem a guarda da criança, sendo este de maior complexidade de fazer provar que é agressora, a criança que deveria estar protegida e guardada sobre a vigia desse guardião, sendo negligenciada pelo mesmo terá maior dificuldade em fazer uma denúncia demonstrar ou pedir ajuda a alguém, ocorre nesses casos além da 
violência uma espécie de coação mesmo que involuntária, e torna uma barreira imensa para a melhoria e diminuição do número de violência contra os tutelados pelo ECA.

O número de violência dentro do âmbito familiar é mais preocupante do que a que ocorre fora dos perímetros familiares, devido a submissão que o menor tem a seus pais ou responsáveis. Assim com a frase "educação vem de casa", é utilizada a torto e direito, um novo bordão deveria ser instaurado na sociedade brasileira a "proteção vem de casa", sendo essa criança negligenciada em seus lares outros tipos de violência externa muita das vezes nem afetará a criança de tal forma que a faça entender de que algo está errado.

\section{CONCLUSÃO}

Diante do presente estudo se conclui-se que os costumes sociais brasileiros no tocante a educação de Crianças e Adolescentes deve sofrer alterações em seus métodos educacionais, tornando-se necessária a delegação de outras funções a entidades diversas a da família como: escolas, grupos sociais e instituições religiosas tornando a sociedade mais participativa na educação em todos os âmbitos, retirando a outorga de responsabilidade total de instrução moral dos pais e responsáveis pelos menores. A violação infanto-juvenil causa profundas marcas em na sociedade e em todo o grupo que tem costumeiramente enfrenta as hostilizações, diminuições e sofrendo a baixa da estima, ocasionando como resposta a mesma violência vivenciada durante seu processo de criação de seu caráter educacional e moral.

O ciclo da violência deve ser quebrado, deve-se alterar o modelo cognitivo dos educadores no tocante aos castigos físicos e psicológicos, leis nada são sem sua efetiva aplicação, não havendo a conscientização dos educadores, pais, membros familiares à lei será apenas mais uma em um milhão de outras.

Criar o costume de reeducar a sociedade é algo que deve ser adotado por nossos legisladores antes do processo legislativo, os responsáveis pelas criações das leis devem analisar o sistema no qual a norma será aplicada, efetuar pesquisas, comparar a realidade do público alvo das medidas legais. O Brasil não mudou em questão aos castigos físicos ou morais, o país não se adequou a realidade legislativa existente nos variados diplomas legais. Serão necessários inúmeros estudos para chegar a uma aplicação eficaz das leis de proteção as crianças e adolescentes em nosso país.

\section{BIBLIOGRAFIA}

BERTOTTI, J. N. Filhos são reflexo do modo de vida dos pais. Gazeta do Povo, 2009. Disponivel em: <http://www.gazetadopovo.com.br/vida-e-cidadania/filhos-sao-reflexo-do-modo-de-vida-dospais-bgnf0wtci4cldonyy8ffqnya6>. Acesso em: 08 ago. 2017.

CMAIS, A. L. V. Lei da Palmada" exige testemunho. CMAIS, 2011. Disponivel em: <http://culturafm.cmais.com.br/comecando/ultimas-noticias/lei-da-palmada-exige-testemunho>. Acesso em: 04 ago. 2017.

E, J. L. B. RELAÇÕES ENTRE ABUSO SEXUAL NA INFÂNCIA, TRANSTORNO DE ESTRESSE. SCIELO, 2008. Disponivel em: <http://www.scielo.br/pdf/pe/v13n2/a20v13n2.pdf>. Acesso em: 08 ago. 2017.

GONÇALVES, L. A. O.; SPOSITO, M. P. Iniciativas públicas de redução da violência escolar no Brasil. SciELO, 2002. Disponivel em: <http://www.scielo.br/scielo.php?script=sci_arttext\&pid=S0100$15742002000100004>$. Acesso em: 20 set. 2017. 
JEANE LESSINGER BORGES, D. D. D. RELAÇÕES ENTRE ABUSO SEXUAL NA INFÂNCIA, TRANSTORNO DE ESTRESSE. Scielo, 2008. Disponivel em: <http://www.scielo.br/pdf/pe/v13n2/a20v13n2.pdf>. Acesso em: 08 ago. 2017.

NASCIMENTO, C. A. D. D. et al. Violência Doméstica Contra. Santo Amaro : EDUPE, 2002.

OLIVIERA, M. Não bata. Eduque! Papo de Mãe, 2010. Disponivel em: <http://www.papodemae.com.br/2010/01/28/nao-bata-eduque/>. Acesso em: 04 ago. 2017.

PLANALTO. LEI № 8.069, DE 13 DE JULHO DE 1990. Presidência da República, 1990. Disponivel em: <http://www.planalto.gov.br/ccivil_03/leis/L8069.htm>. Acesso em: 08 ago. 2017.

PLANALTO. Código Civil Brasileiro. Presidencia da República, Casa Civil, subchfia para assuntos jurídicos, 2002. Disponivel em: <http://www.planalto.gov.br/ccivil_03/leis/2002/L10406.htm>. Acesso em: 04 ago. 2017.

PLANALTO. Constiuição Federal. Planalto, 2017. Disponivel em: <http://www.planalto.gov.br/ccivil_03/constituicao/constituicao.htm>. Acesso em: 20 set. 2017.

RODRIGUES, E. A. P. A DIMENSÃO SOCIAL DA VIOLÊNCIA INFANTO-JUVENIL. Revista UEL, 2010. Disponivel em: <http://www.uel.br/revistas/ssrevista/c_v2n1_violencia.htm>. Acesso em: 19 set. 2017.

RODRIGUES, S. Dirieto Civil - PArte Geral. 34º. ed. São Paulo: Saraiva, v. 1, 2007. 61-63 p.

SPIZZIRRI, A. F. Direito Penal de Proteção a Infância e adolescencia: mudança no paradigma. 61. ed. Porto Alegre: Revista do Ministério Público, 2008.

UNICEFE. Tipos de Violência. UNICEFE BRASL, 2017. Disponivel em: <https://www.unicef.org/brazil/pt/multimedia_27141.htm>. Acesso em: 08 ago. 2017. 